\title{
Corrigendum
}

\section{Nutritional status and human milk intake of exclusively breast-fed infants at high altitude in La Paz, Bolivia - CORRIGENDUM}

Noelia Urteaga, José Luis San Miguel, Ana María Aguilar, Maruska Muñoz and Christine Slater

(First published online 27 June 2018)

doi: https://doi.org/10.1017/S0007114518001137

Original text and correction.

Fig. 1. Z Score length/age by age groups. Must be:

Fig. 1. Example of curves of ${ }^{2} \mathrm{H}$ enrichment in saliva from a mother-infant pair.

Fig. 2. Example of curves of ${ }^{2} \mathrm{H}$ enrichment in saliva from a mother-infant pair. Must be:

Fig. 2. $\mathrm{Z}$ Score length/age by age groups. 